\title{
Considerações sobre ocupações irregulares e parcelamento urbano em áreas de mananciais da região metropolitana de Curitiba-PR
}

\section{Considerations about irregular occupations and urban plot process under the water soucers of Curitiba's metropolitan region}

\author{
Cristina de Araújo LIMA*
}

\begin{abstract}
RESUMO
O artigo apresenta reflexão sobre dados do processo de ocupação no vetor leste de expansão metropolitana, focalizando especialmente os municípios de Pinhais, São José dos Pinhais e Piraquara, onde se localizam mananciais fundamentais para o abastecimento público regional. O esgotamento desses mananciais é um fato previsto para daqui a três décadas, em grande parte acelerado por formas indevidas de ocupação urbana em áreas para as quais o planejamento regional determinou, desde 1978, estratégias de preservação. Atualmente, as ocupações irregulares e invasões crescem aceleradamente, tornando progressivamente mais difícil a conservação ambiental de tais áreas, num contraponto completo às diretrizes planejadas, que não foram implementadas quer seja por obras, investimentos ou ações de gestão do espaço e recursos naturais de importância capital para a manutenção da vida na região metropolitana.
\end{abstract}

Palavras-chave: ocupação urbana metropolitana, degradação de mananciais, planejamento urbano ambiental, parcelamento de solo e degradação ambiental, recursos hídricos em regiões metropolitanas

\begin{abstract}
The article presents reflection about the occupation process data on the expansion of east part of metropolitan region, specially focusing the territory of municipalities of Pinhais, Piraquara and São José dos Pinhais where are fundamental water sources for regional public consumption. The break down of these water resources is foreseen in three decades ahead and this situation was improved by irregular
\end{abstract}

* Doutora em Meio Ambiente e Desenvolvimento e Professora Adjunta do Departamento de Arquitetura da Universidade Federal do Paraná. 
LIMA, C. A. Considerações sobre ocupações irregulares e parcelamento urbano...

forms of occupation of areas where the regional planning had fixed strategy of preservation since 1978. At the present times the irregular occupations and invasions are increasing in a very high speed and proportion what constitute harder situation for conservancy practices.

Key-words: metropolitan sprawl, water sources degradation, environmental urban planning, land use parcels and environmental damage, water sources in metropolitan areas

\section{Introdução}

O processo de parcelamento do solo realizado desde a primeira metade do século XX, em vários municípios que hoje compõem a região metropolitana de Curitiba - RMC, semeou assentamentos precários quanto às condições físico-geográficas e urbanísticas. Aprovados pelas administrações municipais, antes da existência de legislação que definisse as exigências mínimas para a qualidade urbanística dos mesmos, nem todos os loteamentos foram implantados. No entanto, aqueles que o foram, em sua maioria, estabeleceram-se de maneira adversa, ${ }^{1}$ no mínimo, conforme três fatores relativos aos fins a que destinavam-se:

- desconexão da malha urbana existente;

- incompatibilidade de traçado de vias e quadras em relação às características hidro-geomorfológicas da gleba;

- inexistência de infra-estrutura, serviços ou equipamentos urbanos;

Tais características são semelhantes a um modelo de ocupação territorial dispersa e rarefeita que, segundo Bonduki (1988), existiu em vários locais do território nacional, como em São Paulo, a partir da década de $40 .^{2}$

No caso em questão, o parcelamento periférico foi realizado ao redor de uma cidade central, Curitiba, foco de oportunidades de emprego ou trabalho, equipamentos e serviços públicos que a tornavam nos anos anteriores a 1950, um centro para o entorno imediato. Este centro expandiu-se, submeteu-se a normas urbanísticas e, mesmo visando estritamente seu território político-administrativo nas diretrizes de planejamento urbano, teve influência na produção dos espaços vizinhos. Nesses municípios tem se verificado nas últimas décadas a ocupação intensiva de áreas ambientalmente frágeis, porém de importância vital para a qualidade de vida da região metropolitana. Esta situação prejudica especialmente a capital, líder regional no consumo dos recursos hídricos e que, até os anos noventa, foi o lócus principal do crescimento populacional da região metropolitana.

\section{Ocupação urbana em área de mananciais}

No vetor leste de ocupação territorial da RMC, os mananciais de abastecimento público dos rios Iraí e Iguaçu representam $69 \%$ do total da captação para abastecimento público da cidade de Curitiba e municípios vizinhos. A área de estudo aqui focalizada compreende os territórios dos municípios de Pinhais, Piraquara e São José dos Pinhais sobre as sub-bacias contribuintes do Altíssimo Iguaçu e que vêm sendo objeto de intenso processo de parcelamento do solo e ocupação em áreas urbanizadas ou não, dentro do perímetro urbano ou em zonas rurais, desde antes da década de cinqüenta. Há mais de cinqüenta anos, o processo de ocupação acelerou-se adotando uma forma característica, do parcelamento de áreas isoladas da sede urbana municipal, sem infra-estrutura básica para a finalidade de habitação.

Analisando os números na área de estudo verifica-se que a quantidade desses parcelamentos atingiu um pico na década de 50, estendendo uma grade preliminar de 75.729 lotes aprovados regularmente em treze municípios que, em 1974, constituiriam a RMC. No conjunto de grandes nú-

1 Considerando serem loteamentos destinados a população de renda baixa, que teriam melhores condições se inseridos junto à malha urbana existente, onde normalmente já estão disponíveis serviços e equipamentos úteis aos habitantes. Além disso, haveriam outros fatores a considerar como ambiental, paisagístico, econômico, social, e outros.

2 Cf. IBGE, 91/96. 
meros, destaca-se o município de Piraquara, que liderou essa etapa, aprovando mais de 21.000 lotes entre 1950 e 1959, recorde absoluto desde antes de 1950 até os dias atuais. Cabe salientar o fato de grande parte destes parcelamentos serem situados - implantados ou não - em espaços de grande proximidade com o pólo metropolitano, sendo exemplo áreas do município de Colombo ou do território de Pinhais, o qual desmembrou-se de Piraquara em 1992, passando a constituir município.

Desde então, observa-se uma dinâmica regional de ocupação bastante intensa, e que vem acelerando-se, com a taxa de crescimento populacional regional em torno de 3,43\% a.a. em 1996 enquanto a população do Estado crescia a $1,24 \% .{ }^{3}$ Este ritmo acelerado de crescimento, que destacou-se dentre as demais regiões metropolitanas do país, vem a configurar fator determinante para a qualidade de vida dos habitantes, especialmente devido a precariedade de formas de ocupação que ameaçam a conservação de recursos naturais fundamentais para a sobrevivência das formas de vida regiona como a água. Conforme Andreoli et al. (2000), os recursos hídricos regionais estão ameaçados pela expansão metropolitana, cujo processo é centralizado em Curitiba. O esgotamento dos mananciais poderá ocorrer em 35 anos, caso nenhuma medida seja tomada, principalmente em relação a ocupação irregular das áreas dos mananciais, no qual o leste apresenta a situação mais grave. De outro lado da questão, a necessidade de habitação das camadas sociais que ocupam irregularmente as áreas de mananciais segue aumentando, ao longo das décadas, ao compasso do crescimento populacional, tanto vegetativo, quanto de migrações. A questão da contaminação dos mananciais de abastecimento público de água está estreitamente vinculada à realidade econômica e social e depende da capacidade de atendimento às demandas públicas e mobilização do Estado, ou seja, a efetividade das políticas públicas. Nesse contexto, fica caracterizada a omissão do poder público como agravante da crise dos recursos hídricos.

No âmbito das ações do Estado, encontram-se aquelas referentes ao planejamento urbano e regional, o qual objetiva a organização espacial das atividades da socieda- de no território tendo em vista propiciar suporte para as atividades humanas. Como no caso em foco, entre as questões com que o planejamento urbano depara-se no seu processo, que deve ser contínuo, estão aquelas vinculadas às demandas por serviços públicos e equipamentos comunitários. Considera-se que o atendimento a essas solicitações deva levar em conta :

- O ritmo do crescimento populacional (vegetativo + migrações);

- Condições socioeconômicas e culturais da população;

- Formas de ocupação e uso do solo;

- As implicações das formas de ocupação do solo e dos meios de produção com o meio ambiente (os recursos naturais);

- Formas de gestão ou linhas estratégicas de estruturação da ocupação e demandas;

- Viabilidade das diretrizes de planejamento por ações estruturais e não-estruturais e investimentos públicos e privados.

O tema desse artigo está mais fortemente vinculado ao terceiro item - formas de ocupação e uso do solo. Nesse sentido, é pertinente situar-se o caso em foco na perspectiva demográfica regional, sobre a qual pode-se afirmar que o crescimento verificado pela RMC tem sido incrementado por população proveniente de diversas origens do próprio Estado do Paraná, ${ }^{3}$ e de outras regiões do país. A população da região metropolitana atinge a proporção de 2,7 vezes a população referente ao crescimento vegetativo estadual. ${ }^{4}$ Por sua vez, no recorte deste estudo, os municípios de Pinhais, Piraquara e São José dos Pinhais apresentam taxas de crescimento anual, respectivamente, de 3,41\%, $10,86 \%$ e 5,81\%. ${ }^{5}$ Com exceção de Pinhais, os dois outros municípios têm crescimento acima da média regional: Piraquara - município de posição central na rede hidrográfica de abastecimento público regional a lestechegou a crescer 3,16 vezes mais que a taxa da RMC, entre 1991 e 1996. Também significativo foi o crescimento em São José dos Pinhais que, no entanto, foi aproximada-

3 Não são citados os imigrantes provenientes do exterior devido à falta de dados a respeito e a suposta pequena proporção destes no geral da populacional regional, caracterizando-se como casos raros, de pequena interferência na análise.

4 Considerando os dados do IBGE referentes as taxas de crescimento populacional: RMC $=3,43 \%$ a.a. e Estado do Paraná $=1,24 \%$ a.a., conforme citados anteriormente.

5 Tabela de taxas de crescimento dos municípios regionais 1991/96, segundo dados IBGE. Censo demográfico e contagem populacional. 
LIMA, C. A. Considerações sobre ocupações irregulares e parcelamento urbano...

mente a metade do que houve em Piraquara $(53,49 \%)$, no mesmo período.

Transformando as taxas de crescimento em números de habitantes, verifica-se, no caso de Piraquara, que a cada ano 2.102 novos habitantes passam a integrar a população municipal. Os números sinalizam o volume das demandas socioeconômicas e urbanísticas a serem atendidas, como vagas no serviço público de atendimento de saúde, em escolas, em número de empregos, dentre outros itens.

Considera-se que esses dados demográficos podem propiciar reflexões sobre a responsabilidade social das políticas públicas em geral enquanto os as autoridades, que são tomadores de decisão, tem por dever a defesa dos bens e interesses da coletividade. Os dados também podem colocar em questão aspectos físicos do desenvolvimento urbano, em cuja base está a utilização de recursos naturais.
Além dos números relativos ao crescimento populacional, cabe considerar fatores como a renda familiar da população da periferia metropolitana. Na RMC, dados do IBGE provenientes do censo populacional de 1991, apresentam a taxa de $40,12 \%$ relativa aos chefes de família que recebem até dois salários mínimos por mês; 33, $11 \%$ chegam a ganhar até cinco salários mínimos mensais. Ou seja, na parcela com teto salarial de dois salários, provavelmente as necessidades básicas consumirão o salário. Mesmo entre aqueles cujos rendimentos não ultrapassam os cinco salários, considerando uma família de três a quatro pessoas, ${ }^{6}$ o padrão de vida será um tanto restrito para formação profissional de nível médio a alto, acesso ao conhecimento atualizado, novas tecnologias, e inúmeros exemplos de atividades de crescimento do potencial humano. Como conseqüência, caberá ao próprio Estado su-

TABELA 1 - RMC - EVOLUÇÃO DAS OCUPAÇÕES IRREGULARES ENTRE 1992 E 1997

\begin{tabular}{|c|c|c|c|c|c|}
\hline Município & $\begin{array}{l}\mathrm{N}^{\circ} . \text { de unidades } \\
\text { em } 1992\end{array}$ & $\begin{array}{l}\text { N. }{ }^{\circ} \text { de unidades } \\
\text { em } 1998\end{array}$ & $\begin{array}{l}\text { População em } \\
\text { ocupações } \\
\text { irregulares } 1992\end{array}$ & $\begin{array}{l}\text { População em } \\
\text { ocupações } \\
\text { irregulares } 1998\end{array}$ & $\begin{array}{l}\text { Taxa de } \\
\text { crescimento } \\
1992 / 98\end{array}$ \\
\hline Adrianópolis & 0 & 93 & 0 & 344 & $\mathrm{~N} / \mathrm{d}$ \\
\hline Agudos do Sul & 0 & 0 & 0 & 0 & $\mathrm{~N} / \mathrm{d}$ \\
\hline Almirante Tamandaré & 1.536 & 4.785 & 6.451 & 17.705 & 18,32 \\
\hline Araucária & 509 & 1.552 & 2.102 & 5.742 & 18,23 \\
\hline Balsa Nova & 0 & 0 & 0 & 0 & $\mathrm{Nd}$ \\
\hline Bocaiúva do Sul & 27 & 127 & 107 & 470 & 27,97 \\
\hline Campina Grande do Sul & 188 & 584 & 788 & 2.161 & 18,31 \\
\hline Campo Largo & 423 & 730 & 1.709 & 2.701 & 7,93 \\
\hline Campo Magro & $\mathrm{O}$ & 1.723 & 0 & 6.375 & $\mathrm{~N} / \mathrm{d}$ \\
\hline Cerro Azul & 0 & 42 & 0 & 155 & $\mathrm{~N} / \mathrm{d}$ \\
\hline Colombo & 3.303 & 6.253 & 13.740 & 23.136 & 9,07 \\
\hline Contenda & 49 & 66 & 209 & 244 & 2,63 \\
\hline Curitiba* & 44.713 & 53.162 & 165.438 & 196.699 & 2,93 \\
\hline Doutor Ulysses & 0 & 0 & 0 & 0 & $\mathrm{~N} / \mathrm{d}$ \\
\hline Fazenda Rio Grande & 440 & 1.557 & 1.874 & 5.761 & 20,58 \\
\hline Itaperuçu & 155 & 572 & 660 & 2.116 & 21,43 \\
\hline Mandirituba & 21 & 31 & 89 & 115 & 4,32 \\
\hline Pinhais & 1.556 & 2.293 & 6.302 & 8.484 & 5,08 \\
\hline Piraquara & 197 & 4.199 & 648 & 15.536 & 69,81 \\
\hline Quatro Barras & 0 & 0 & 0 & 0 & $\mathrm{Nd}$ \\
\hline Quitandinha & 0 & 0 & 0 & 0 & $\mathrm{~N} / \mathrm{d}$ \\
\hline Rio Branco do Sul & 463 & 817 & 1.972 & 3.023 & 7,38 \\
\hline São José dos Pinhais & 581 & 3.838 & 2.353 & 14.201 & 34,93 \\
\hline Tijucas do Sul & 0 & 0 & 0 & 0 & $\mathrm{~N} / \mathrm{d}$ \\
\hline Tunas do Paraná & 0 & 0 & $\mathrm{O}$ & 0 & $\mathrm{~N} / \mathrm{d}$ \\
\hline TOTAL & 54.161 & 82.446 & 204.442 & 305.050 & 6,90 \\
\hline
\end{tabular}

FONTE: COMEC, 1992/1997.

* IPPUC /COHAB-CT 
prir espaços públicos com recursos materiais e humanos para o desenvolvimento dos seus cidadãos. Porém, antes das condições complementares para a qualidade de vida, existem na área em estudo, questões fundamentais a serem resolvidas.

Na RMC, percebe-se como um dos maiores desafios para o poder público, a questão habitacional, que remete a direitos e necessidade elementares de qualquer ser humano. Antes mesmo de melhoria dos padrões habitacionais existentes, visando otimização do consumo de energia, ou utilização de materiais e processos ambientalmente menos impactantes, há que se verificar as condições de pobreza existentes no âmbito metropolitano, em que as subhabitações configuram uma solução para carência extremada, um problema socioeconômico de responsabilidade do Estado. Nesse aspecto, é pertinente analisar a escala assumida pelo problema das ocupações irregulares da região, com números da tabela 1 .

A questão habitacional encontra-se centrada na falta de opções de acesso a moradia para as camadas de baixa renda. Este hiato crescente, no contexto do processo de expansão da RMC, assume cada vez mais uma posição de importância crucial devido aos desdobramentos que produz, dentre os quais se enfatiza, neste artigo, a degradação do meio ambiente. Tratando-se da questão da ocupação urbana por parcelamentos em área de mananciais de abastecimento público, é necessário antes de prosseguir com a análise, verificar dados sobre o comprometimento da ocupação em áreas de municípios que não se limitam as fronteiras político-administrativas, configurando recortes físicos próprios dos ecossistemas. As áreas utilizadas pelos recursos naturais em sua dinâmica físico-biológica, como os corpos d'água formatam bacias passando pela interligação das sub-bacias hidrográficas. Nesse aspecto do caso em foco, destaca-se a interligação e disseminação da poluição entre os rios e a situação da contaminação gerada a montante que se alastra pelas áreas à jusante. Levando em consideração a localização das duas captações da Sanepar na bacia do Alto Iguaçu, uma delas no Rio Iraí, entre os municípios de Piraquara e Pinhais, e a outra no rio Iguaçu, no município de São José dos Pinhais, divisa com Curitiba, verifica-se que a contaminação das sub-bacias decorrentes de ocupações, regulares e irregulares, observadas na área de estudo, apresenta-se previamente carregada desde o município de Colombo através do rio Palmital que avoluma-se à altura de Pinhais.

A várzea do rio Palmital vem sendo progressivamente ocupada de forma irregular desde os anos 70, e tornandose um manancial que, constantemente beira os limites mínimos aceitáveis de uso para abastecimento, transformouse num grande foco de contaminação para outros braços da rede. Uma das razões dessa situação são ocupações como a conhecida por "Zumbi dos Palmares", localizada no município de Colombo, uma das três maiores ocupações regionais, que apresentava mais de 1.000 unidades de subhabitações em 1997 (COMEC, 1998), ou seja, uma população de cerca de 3.800 habitantes $^{7}$ assentados sem infraestrutura sobre leito de inundação do rio. O rio Palmital, encontra o rio Iraí na divisa entre os municípios de Pinhais e Piraquara e, mais à frente, na divisa com Curitiba, une-se ao rio Atuba, no chamado "Marco Zero do Iguaçu." Na bacia do "Altíssimo Iguaçu” é produzida 69,23\% da água que alimenta o principal sistema de abastecimento público regional, junto à BR-277, denominado "Sistema Integrado Curitiba". Este sistema abastece Curitiba, Araucária, Colombo (em cerca de 50\%), Pinhais e São José dos Pinhais. Apesar de óbvio, parece importante ressaltar a dinâmica natural dos rios que é desvinculada dos limites impostos pelo homem.

Também, quando analisam-se os dados como os apresentados na tabela 1 , percebe-se que os números representam indicadores de uma realidade concreta, ainda mais abrangente, que perfaz todo um quadro de qualidade de vida. Entre 1992 e 1997, o número de ocupações irregulares nos municípios do leste metropolitano, enfocados no trabalho - Pinhais, Piraquara e São José dos Pinhais cresceu cerca de 4,5 vezes em cinco anos - o que pode significar que a cada ano instalaram-se precariamente nestes municípios, cerca de 5.783 pessoas ou , a cada dia, mais de 15 pessoas, ou 4 famílias, considerando a média regional de componentes da unidade familiar da Comec. ${ }^{8}$ Este valor atinge em 1997, um total no valor de 38.221 pessoas, nos três municípios, em estado de carência generalizada, pois as ocupações irregulares normalmente formam um

7 COMEC, op. cit

8 Adotando a média entre os valores dos três municípios ou 3,67 pessoas/domicílio, segundo Comec (1999). 
LIMA, C. A. Considerações sobre ocupações irregulares e parcelamento urbano...

FIGURA 1 - OCUPAÇÕES E INVASÕES

\section{Figura 1}

FONTE: COMEC, 2000.

quadro de precariedade, não apenas quanto aos assentamentos em si, na sua materialidade, mas principalmente quanto a precariedade sóciocultural implicada, de formação do indivíduo em sua totalidade, como profissional, cidadão, como Ser.

A respeito da evolução do número de ocupações irregulares na região metropolitana, cabe destacar que o número de unidades verificado nos três municípios em foco - área de mananciais - é 2,9 vezes maior que o valor apresentado pela RMC no mesmo período, ${ }^{9}$ conforme apresentado na figura 1.

A variação das taxas de crescimento das ocupações irregulares ocorridas nos municípios da região metropolitana entre 1992 e 1997, configurou focos para tal tipo de

9 Na RMC, o crescimento do número das ocupações irregulares cresceu 152,22\% durante os cinco anos contemplados , enquanto em Pinhais , Piraquara e São José dos Pinhais, o crescimento das unidades foi de $442,58 \%$ no mesmo período. Cf. Comec, op. cit. 
LIMA, C. A. Considerações sobre ocupações irregulares e parcelamento urbano...

FIGURA 2 - LOCALIZAÇÃO ÁREAS OCUPADAS IRREGULARMENTE E GRANDES INVASÕES

Figura 2

FONTE: COMEC, 2000.

assentamento. Ao reverso do que preconizava o Plano de Desenvolvimento Integrado da RMC, PDI, aprovado em $1978^{10}$, verificam-se os maiores números de assentamentos irregulares encontram-se no município de Piraquara, com uma taxa estonteante de 69,81\%, seguido por São José dos Pinhais e Bocaiúva dos Sul.
O trio de municípios que, na seqüência apresentam os valores em quarto, quinto e sexto lugares relativos a taxa de crescimento de ocupações irregulares 1992/98, reproduzem outra tendência bastante expressiva como ocupação urbana, tanto regular como irregular, que é o vetor norte-sul de expansão metropolitana. No caso, tem-se os

10 Referência ao plano regional elaborado pela Comec, aprovado em 1978, reavaliado em 1991 e atualmente em novo processo de avaliação. 
LIMA, C. A. Considerações sobre ocupações irregulares e parcelamento urbano...

TABELA 2 - MUNICÍPIOS DE PINHAIS, PIRAQUARA, SÃO JOSÉ DOS PINHAIS E CURITIBA EVOLUÇÃO DAS OCUPAÇÕES IRREGULARES 1992 E 1997

\begin{tabular}{|c|c|c|c|c|c|}
\hline Município & $\begin{array}{lr}\text { N. }^{\circ} & \text { de } \\
\text { unidades } & \text { em } \\
1992 & \end{array}$ & $\begin{array}{lr}\mathrm{N}^{\circ} & \mathrm{de} \\
\text { unidades } & \mathrm{em} \\
1997 & \end{array}$ & $\begin{array}{l}\text { População em } \\
\text { ocupações } \\
\text { irregulares } \\
1992\end{array}$ & \begin{tabular}{|l} 
População em \\
ocupações \\
irregulares \\
1997 \\
\end{tabular} & $\begin{array}{l}\text { Taxa de } \\
\text { crescimento } \\
1992 / 97\end{array}$ \\
\hline Pinhais & 1.556 & 2.293 & 6.302 & 8.484 & 5,08 \\
\hline Piraquara & 197 & 4.199 & 648 & 15.536 & 69,81 \\
\hline São José dos Pinhais & 581 & 3.838 & 2.353 & 14.201 & 34,93 \\
\hline Curitiba * & 44.713 & 53.162 & 165.438 & 196.699 & 2,93 \\
\hline $\begin{array}{l}\text { TOTAL Recorte de estudo } \\
\text { Pinhais, Piraquara e São } \\
\text { José dos Pinhais }\end{array}$ & 2.334 & 10.330 & 9.303 & 38.221 & $\begin{array}{l}\text { Média três } \\
\text { municípios: } \\
36,60\end{array}$ \\
\hline $\begin{array}{l}\text { Porcentagem valores de } \\
\text { Pinhais, Piraquara e São José } \\
\text { dos Pinhais em relação ao } \\
\text { total MC }\end{array}$ & $4,30 \%$ & $12,52 \%$ & $4,55 \%$ & $12,52 \%$ & $62 \%$ a.a. \\
\hline TOTAL RMC & 54.161 & 82.446 & 204.442 & 305.050 & 6,90 \\
\hline
\end{tabular}

FONTE: COMEC 1992/1997.

* IPPUC /COHAB-CT

municípios de Itaperuçu, Fazenda Rio Grande e Almirante Tamandaré - com as taxas de crescimento respectivas de $21,43 \%, 20,58 \%$ e $18,32 \%$.

A seguir, neste escalonamento, estão Campina Grande do Sul, com 18,31\%, Araucária 18,23\% e Colombo com valor de $9,07 \%$, reforçando a ocorrência de ocupações irregulares nos municípios do leste e norte metropolitano. No entanto, essa tendência dispersa-se no grupo seguinte, quando Campo Largo, no oeste, vem ocupar o décimo lugar seguido por Rio Branco do Sul e Pinhais, este último integrante do recorte geográfico deste estudo. Depois, fechando os trios, tem-se os municípios dos quais os dados estão disponíveis e que no caso, apresentam os menores índices de crescimento de ocupação irregular da RMC. São eles: Mandirituba $(5,08 \%)$, Curitiba $(2,93 \%)$ e Contenda $(2,63 \%)$. Todavia, estes valores não podem ser considerados isoladamente, em razão de dez municípios não terem expressas suas taxas de crescimento das ocupações irregulares. Portanto, fazse as considerações a seguir considerando para efei- tos da somatória, os agrupamentos de municípios em concordância com os subsistemas da RMC definidos pelo plano regional em vigor - Plano de Desenvolvimento Integrado/PDI.

Desta forma, considerando a população residente em ocupações irregulares, verifica-se que o maior número encontra-se localizado nos municípios do subsistema norte com total de 52.591 pessoas, seguido pelo subsistema leste - de mananciais, com 26.986 moradores de áreas irregulares. $\mathrm{O}$ subsistema sul fica em terceiro lugar e o oeste em última posição. ${ }^{11}$ A figura 2, apresenta a localização das maiores ocupações da RMC.

Parece pertinente salientar a gravidade das ocupações localizadas em áreas de mananciais, no caso, ao leste, sobre mananciais superficiais e também na direção norte, sobre mananciais subterrâneos cársticos. Além disso, cabe igualmente destacar o grande número de ocupações efetivadas no município de São José dos Pinhais - no PDI situado no vetor sul da RMC, mas que contém significativas áreas de mananciais que integram-se ao leste - o qual apre-

11 Caso fossem consideradas apenas as taxas de crescimento das ocupações irregulares entre 1992 e 1997, o resultado sairia distorcido em razão de haverem dados de municípios desmembrados neste intervalo de tempo que não são disponíveis ou de municípios incorporados nos quais estes dados inexistem. Por outro lado, as taxas de crescimento geralmente podem indicar uma tendência, mas não o volume de ocorrências, que são de interesse ao estudo. 
LIMA, C. A. Considerações sobre ocupações irregulares e parcelamento urbano...

TABELA 3 - TAXA DE CRESCIMENTO DE OCUPAÇÕES IRREGULARES 19921997 - COMPARATIVAMENTE A TAXAS DE CRESCIMENTO DA POPULAÇÃO URBANA EM $1996\left({ }^{1}\right)$

\begin{tabular}{l|l|l}
\hline Municípios & $\begin{array}{l}\text { Porcentagem da } \\
\text { população urbana em } \\
\text { ocupações irregulares } \\
92 / 97\end{array}$ & $\begin{array}{l}\text { Taxa de crescimento } \\
\text { das } \\
\text { irregulares 92/97 }\end{array}$ \\
\hline Pinhais & 9,36 & 5,08 \\
\hline Piraquara & 37,61 & 69,81 \\
\hline São José dos Pinhais & 6,78 & 34,93 \\
\hline $\begin{array}{l}\text { Média no recorte do } \\
\text { estudo }\end{array}$ & 17,91 & 36,60 \\
Média da RMC & $2,33\left(^{2}\right)$ & 6,90 \\
\hline
\end{tabular}

FONTE: COMEC, 1992/1997.

NOTAS: - 1 Considerando a população urbana da Contagem IBGE 1996 e dados interpolados para 1996 relativos a ocupações irregulares registradas em levantamento de campo realizado em 1998 pela Comec.

2 Cálculo realizado com a interpolação da população em ocupações irregulares para 1996 proveniente de dados de levantamento Comec 1998. A população urbana total da RMC é proveniente de IBGE - Contagem populacional 1996. Assim foi considerado o total de 271.514 pessoas sendo a população em ocupações irregulares na RMC 1996, e o total de população urbana da RMC em 1996, o número de 2.201.577 habitantes.

GRÁFICO 1 - MUNICÍPIOS DE PINHAIS, PIRAQUARA E SÃO JOSÉ DOS PINHAIS COMPARATIVO ENTRE POPULAÇÃO URBANA E POPULAÇÃO DE OCUPAÇÕES IRREGULARES EM 1996 (EM PORCENTAGEM)

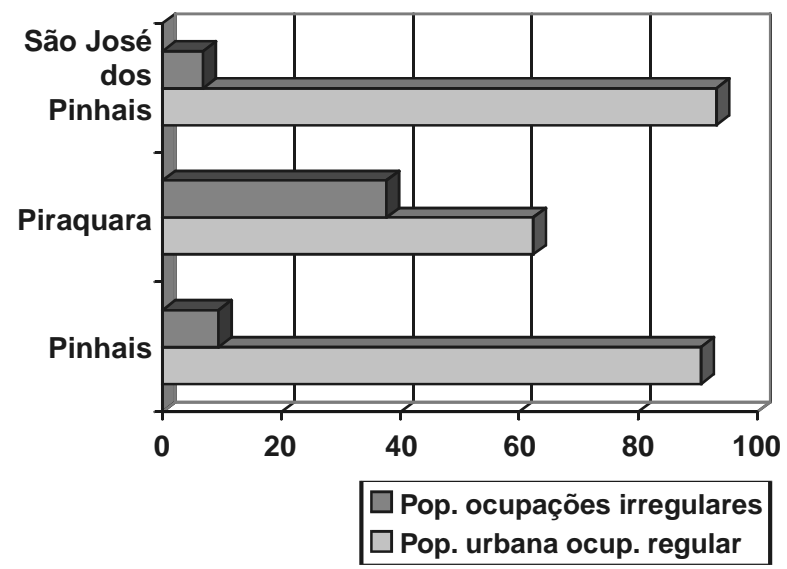

FONTE: COMEC, 1999. senta o segundo maior número de ocupações em mananciais da região metropolitana, com taxa de crescimento em $34,93 \%$ entre 1992 e 1997, como observa-se nos dados da tabela 2 .

Na relação entre o recorte espacial deste estudo e o montante total de ocupações irregulares na região metropolitana, verifica-se que nos municípios em foco concentram-se $12,5 \%$ do total de população residente em subhabitações em toda a RMC. ${ }^{12}$ Da população total, a parcela assentada em ocupações irregulares, em cada município é, em Pinhais 9,36\%, em Piraquara 37,61\% e em São José dos Pinhais 6,78\% (tabela 3). ${ }^{13}$

Ao confrontar estes valores de taxas de crescimento das ocupações irregulares na RMC comparativamente aos que apresentam a porcentagem da população urbana residente em ocupações irregulares nos três municípios da área de mananciais em foco, tem-se que a média do recorte do estudo assume o valor de 17,91\%, o que representa 7,68 vezes a média regional. Também, comparando as taxas de crescimento das ocupações irregulares no recorte enfocado entre os dois períodos dos levantamentos da Comec/Ippuc/

12 Considerando análise realizada antes da publicação do Censo 2000.

13 COMEC. Proposta para Área de Interesse Social AISO do Guarituba/Piraquara. Curitiba, 1999. 

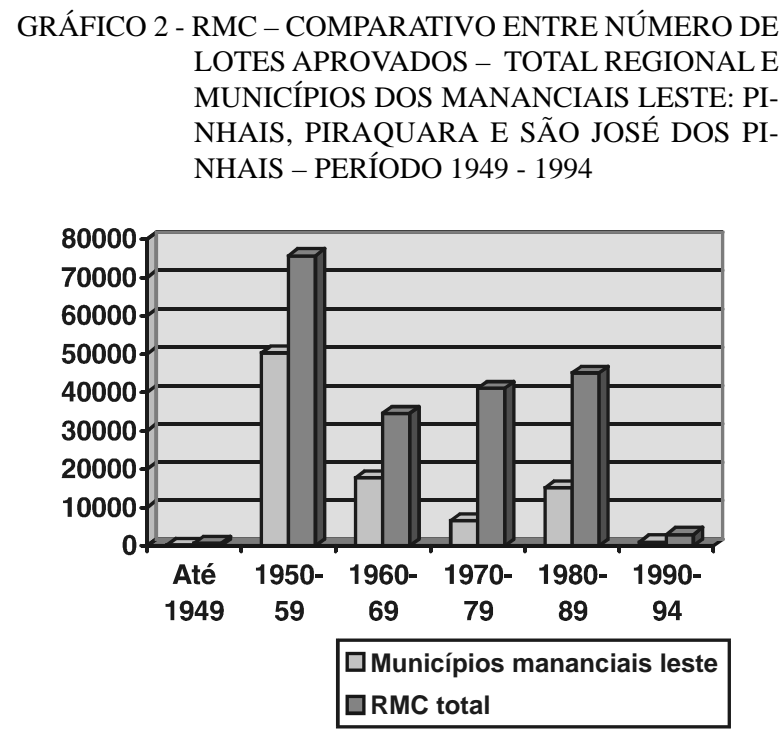

FONTE: COMEC, 1999.

Cohab realizados em 1992 e 1997, verifica-se uma taxa dos municípios de Pinhais, Piraquara e São José dos Pinhais de $36,60 \%$ ou 5,3 vezes a média da RMC, como apresenta-se na tabela 3 .

Analisando os dados da tabela 3 , percebe-se $a$ excepcionalidade da situação do município de Piraquara em relação aos demais municípios componentes da tabela, e mesmo em comparação a toda a RMC. Esse é o município que apresenta o maior número de pessoas assentadas em ocupações irregulares em toda a RMC. Além de possuir uma porcentagem bastante representativa da população urbana residente em ocupações irregulares - chegando mais de três vezes a já alta taxa regional, em Piraquara também, a taxa de crescimento das ocupações é extremamente alta, demonstrando a tendência de agravamento da situação. Caso fossem atribuídos pesos iguais para os dois enfoques da questão, o valor observado com esta média para o município de Piraquara seria mais de 2,5 vezes o valor sequencialmente maior, que é o verificado no município de São José dos Pinhais. ${ }^{14}$
Logo, conclui-se que as ocupações irregulares de maior amplitude quanto à dimensão espacial situam-se em áreas metropolitanas menos adequadas a recebê-las, no caso, em razão da sua localização em áreas de mananciais de abastecimento público de água, tanto ao norte como à leste e sudeste da região. O grande destaque fica com os municípios de Piraquara e São José dos Pinhais, que apresentam números muito altos, especialmente Piraquara. Esta constatação demonstra risco ambiental advindo do processo de ocupação que atinge áreas de mananciais de abastecimento público de água tão importantes, como nos municípios destacados.

No gráfico 1, demonstra-se a proporção entre a população urbana e a parcela desta que encontra-se assentada irregularmente nos municípios em foco na área de estudo.

Em relação aos municípios situados em áreas de mananciais, destaca-se no aquíffero subterrâneo karst, ao norte da metrópole, o extremamente rápido crescimento urbano dos municípios de Almirante Tamandaré e Colombo. À leste, na bacia do Altíssimo Iguaçu, os municípios de Campina Grande do Sul e Pinhais; à oeste Araucária; ao sul Fazenda Rio Grande e no centro Curitiba, o pólo metropolitano que teve acréscimo de 730 mil habitantes em cerca de vinte anos.

Em grande velocidade e proporção, a ocupação urbana tem-se acentuado sobre áreas sem infra-estrutura ou redes de serviços e equipamentos urbanos para receber tal contingente populacional. Verifica-se, também, a grande expressão que tais contingentes populacionais provocam no contexto geral da ocupação regional, no caso, do contexto relativo ao espaço físico-geográfico, passando pelas estruturas urbanas até o meio ambiente - no qual destacase o recurso água. Quanto às interferências no espaço urbano, cabe lembrar que apropriações do espaço em tal escala e velocidade têm efeitos prolongados e acima de tudo efeitos multiplicadores de degradação ambiental.

No gráfico 2, representa-se uma síntese que confronta os números de lotes aprovados na RMC com os lotes aprovados nos municípios do recorte do estudo comentado nesse artigo. Observa-se que a porcentagem de parcelamento de solo nos municípios estudados é muito significativa, em relação ao total de lotes aprovados em toda a RMC. Esta posi-

14 O cálculo realizado foi a média simples, em que somaram-se os dois valores apresentados por cada município e dividiu-se por dois. No caso, para Pinhais, a média foi de 7, 22.; para São José dos Pinhais a média foi de 20, 85 pontos e a média para Piraquara foi de 53,71 pontos. 
LIMA, C. A. Considerações sobre ocupações irregulares e parcelamento urbano...

ção evidencia-se, especialmente, entre as décadas de 50 e 60. Na década de 70, esta concentração atinge as menores taxas do período observado, exceto o período "até 1949" e "1990-94". Justapondo-se os dados referentes ao incremento populacional entre 1970 e 1996 (IBGE) e também o número de lotes aprovados na RMC (Comec), no mesmo período, verifica-se que os municípios que compõe o recorte do estudo tiveram uma variação de $680,35 \%$ de crescimento populacional, enquanto a região metropolitana atingiu $886,09 \%$ e Curitiba $152,57 \% .{ }^{15}$ Do montante populacional é importante evidenciar a parcela de população acrescentada após o censo demográfico de 1980 nos municípios de Pinhais, Piraquara e São José dos Pinhais, e a característica de $45,41 \%$ dessa população ter renda mensal entre zero $e$ dois salários mínimos.

O fato da ocupação urbana nos municípios que possuem mananciais de abastecimento público de água em seus territórios, está registrada em textos das propostas do órgão de planejamento metropolitano, a Comec, que atualmente reavalia o plano regional. Sobre a evolução do crescimento populacional nas áreas de mananciais,

...verifica-se que nas áreas limítrofes à capital, a população foi decuplicada num período de 26 anos, enquanto Curitiba teve seu contingente populacional aumentado em aproximadamente $150 \%$. O crescimento populacional nas áreas de mananciais ocorreu apesar das restrições quanto ao parcelamento do solo previstas nas legislações estadual e municipais. Contrariamente às especulações de que esse processo iniciou-se após o recente processo de industrialização na região, os dados do IBGE demonstram que o processo de ocupações irregulares que vem ocorrendo iniciou-se à partir do início de noventa, quando instalaram-se as grandes invasões : Zumbi dos Palmares em Colombo no ano de 1990, Jardim Alegria em São José dos Pinhais em 1992 e Guarituba entre 1994 e $1995 .{ }^{16}$
Também no mesmo texto, é feita uma observação relativa à produção de lotes populares pelo poder público, o qual, no período entre 1985 e 1991, destinou apenas $13 \%$ das unidades para toda a região metropolitana, enquanto o pólo regional absorveu os demais $87 \%$ ou 16.588 unidades de moradia popular. Destas informações, pode-se ler o interesse público voltado à preservação da qualidade do meio urbano do pólo regional, em detrimento da região metropolitana. Esse baixo índice de atendimento à demanda habitacional de baixa renda tanto pode ser resultado de falta de capacidade de gerência das autoridades encarregadas, ou da falta de recursos ou da pauta de questões do governo não contemplar tais demandas como prioritárias. Em qualquer dos casos, a reversão deste quadro de pobreza periférica ao pólo metropolitano é bastante difícil por depender de políticas públicas eficientes quanto a melhoria da renda, o que considera-se consequiência da melhoria das próprias condições de articulação da melhor formação profissional e da existência de oportunidades de emprego e renda. ${ }^{17}$ Por fim, os aspectos da ocupação do território, em especial o caso das ocupações irregulares que contribuem

\section{GRÁFICO 3 - MUNICÍPIO DE PIRAQUARA - CONCENTRA- ÇÃO LOCACIONAL DA POPULAÇÃO 1996}

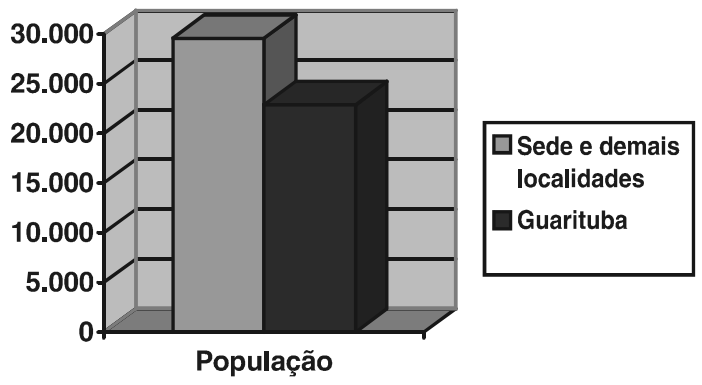

FONTE: IBGE, 1999.

15 Em 1970, os municípios de Pinhais, Piraquara e São José dos Pinhais possuíam juntos 33.588 habitantes. Em 26 anos, em 1996, passaram a somar 262.105 habitantes. Já a RMC, excluindo Curitiba, teve incremento de 76.089 habitantes até 750.307 habitantes. Também os 584.481 curitibanos registrados em 1970 somavam 1.476.253 em 1996. COMEC. Proposta..., op. cit.

16 Id. (grifo nosso).

17 Dentre fatores agravantes da situação, está a inexistência de bases para a geração de dinâmica econômica regional que buscasse formas alternativas de criar e manter renda e/ou oportunidades de emprego e renda voltadas para os níveis mais elementares de formação, com a finalidade última de alavancar a melhoria do perfil geral do habitante da RMC, como em cooperativas de trabalho comunitário, com produtos para o mercado nacional e internacional. Neste aspecto, considera-se a implantação das montadoras na RMC como fator gerador de renda cuja escala de retorno perde significado quando consideradas as proporções dos níveis de pobreza da metrópole, com quase metade da população com nível de renda entre zero e dois salários mínimos. 
LIMA, C. A. Considerações sobre ocupações irregulares e parcelamento urbano...

negativamente para a degradação de recursos naturais, estão diretamente ligados ao sucesso ou insucesso de políticas mais abrangentes. $\mathrm{O}$ valor comercial do solo urbano ao ser incrementado pelas determinações do planejamento urbano, exclui grande parcela de população, de menor renda, da inserção legal na malha urbana.

A ocupação veloz e contundente da periferia de Curitiba e, especialmente, as áreas localizadas junto à mananciais de abastecimento público, situados no vetor leste de expansão metropolitana, tem seu processo ligado à própria dinâmica de ocupação urbana que transcorreu em Curitiba, originada em meados da década de 1940, refletindo-se nos anos 50 com maior intensidade na forma de loteamentos esparsos.

Essa ocupação vai se consolidando lentamente pelas vias comerciais normais, tendo em vista a perda de valor de venda dos lotes devido à legislação de uso do solo ser bastante restritiva. Este vazio de ocupação, aliado à necessidade de moradia para camadas de baixa renda, em geral, vai gerar a partir de 90, invasões e ocupações irregulares, conformando um quadro preocupante de degradação social e ambiental mais complexo, sendo que no vetor leste da metrópole, a ocupação chegou às margens dos seus mananciais.

\section{Piraquara}

O lento processo de ocupação que se verificava na região foi alterado com a formação de colônias de imigrantes, após 1850. Na área de estudo em questão, o município de Piraquara foi um dos municípios da atual região metropolitana de Curitiba que recebeu parte deste contingente de mão-de-obra. ${ }^{18}$

O município de Piraquara apresentava população de 106.882 habitantes pelo censo IBGE 1991, sendo deste total 91.438 (85,55\% do total) moradores da área urbana e 15.444 $(14,45 \%)$ da área rural. Já, conforme a contagem efetuada pelo IBGE em 1996, a população apresentava uma taxa de crescimento negativa $(-13,26 \%)$ com o total restrito a 52.486 habitantes. Esse decréscimo no montante populacional deve-se ao desmembramento do distrito de Pinhais, transformado em Município em 18/03/1992. No entanto, enquanto a população urbana decrescia, segundo dados IBGE/Comec, houve um acréscimo de população devido a ocupações de áreas rurais, localizadas em mananciais de abastecimento público.

Do total da população registrada pela contagem do IBGE em 1996, com total de 52.486 habitantes no município, 43,63\% eram moradores da área do Guarituba, quase metade do contingente populacional total. Isto significa 22.900 pessoas habitando em condições inadequadas na base física e social. Trata-se de área inundável, com lençol freático aflorante que dificulta a estruturação dos serviços urbanos básicos, como o funcionamento de redes de esgotamento sanitário ou mesmo do sistema de fossas sépticas. Além destes fatores agravantes, esta ocupação localiza-se em área de mananciais de abastecimento público de água. Devido a estas condições de precariedade do assentamento, são deficientes as instalações de serviços públicos urbanos e equipamentos de todo tipo, quer seja transporte, como educação, saúde ou lazer. Pelo gráfico 3, vê-se os montantes populacionais das duas situações.

Como apresentado anteriormente, no âmbito do planejamento regional, o município de Piraquara, juntamente com seus vizinhos - municípios de Campina Grande do Sul, Quatro Barras e, mais tarde Pinhais ${ }^{19}$ - conformaram uma secção regional que foi denominada de "subsistema leste", por definição do Plano de Desenvolvimento Integrado - PDI/1978.

Por este Plano, Piraquara exerceria a liderança deste subsistema visando equilibrar o desenvolvimento urbano de localidades e distritos próximos, como Pinhais - já com população superior à sede e conurbado a Curitiba - e também para servir de apoio à atividades rurais como a

formação de uma bacia leiteira apta a abastecer o mercado metropolitano e as de preservação ecológica, evitando a ocupação despropositada do território a leste de Curitiba por tecidos urbanos de toda sorte de densidade. $^{20}$

18 Como ocorreu também com outras localidades depois transformadas em municípios como Almirante Tamandaré, Bocaiúva do Sul e Colombo, dentre outros. 19 Àquela época ainda distrito do município de Piraquara. Seu desmembramento vai ocorrer em 18/03/1992.

20 Comec. PDI, op. cit. 
Seguindo a sequiência de prioridades regionais, após a elaboração do plano metropolitano a coordenação da região metropolitana de Curitiba passou a apoiar os municípios na elaboração de seus Planos Diretores Municipais. Dois anos após, em 1980, o Plano Diretor de Piraquara foi aprovado. Este Plano previa uma ocupação por atividades residenciais, de transformação como indústrias e serviços de forma controlada na sede e voltada à preservação urbana em localidades como Guarituba, cujo processo de parcelamento e ocupação é proveniente de algumas décadas. $^{21}$

Como a ocupação sobre áreas de mananciais prossegue, uma vez originada há algumas décadas e, portanto, previamente à existência do planejamento regional, a instituição de planejamento regional Comec, decidiu readequar os paradigmas anteriores propostos para tal questão. A expansão urbana foi direcionada para o sul, e para as áreas de mananciais à leste, foi elaborada pela Comec a proposta de ordenamento, cuja premissa é limitar a densidade populacional pela capacidade de esgotamento sanitário e de drenagem das áreas. Esta proposta foi base para a chamada "lei dos mananciais", à nível Estadual, de n. 12.248 aprovada em 31/07/98.

Quanto ao uso e ocupação do solo, o município de Piraquara reunia em seu território, segundo a contagem realizada pelo IBGE em 1996, uma população urbana de 28.109 habitantes. A área urbana está organizada segundo a Lei Municipal n. ${ }^{\circ}$ 12/80 sancionada em 06/11/1980, a

GRÁFICO 4 - MUNICÍPIO DE PIRAQUARA - ÁREA LOTEADA NA SEDE E GUARITUBA EM HECTARES

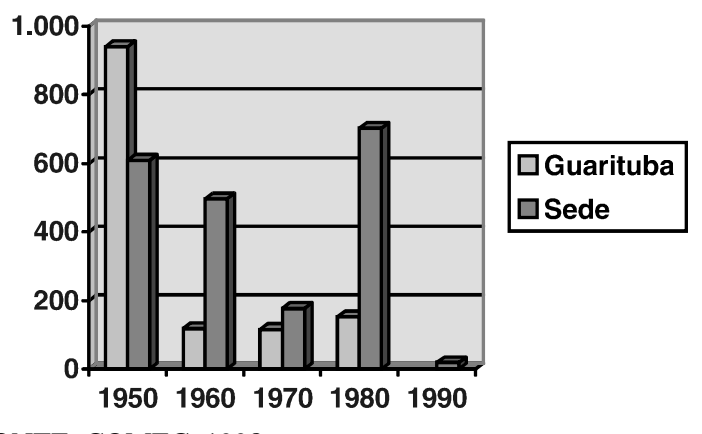

qual dispõe sobre o zoneamento do Distrito Sede e outras providências. Também estão em vigor a Lei Municipal n. ${ }^{\circ}$ 62, de 01/06/1982, que dispõe sobre o zoneamento da ZPU - Zona de Preservação Urbana, e a Lei Municipal n. o 388/ $^{2}$ 98 de 10/09/1998, que cria a Zona Especial de Serviços ZES. A área urbana, legalmente instituída, não apresenta maiores problemas ambientais, devido a estar situada em terreno adequado, lócus da formação original. Atualmente, tem recebido novos moradores que tendem a aglutinarse em áreas próximas à sede, com ligação viária e transporte coletivo com linha direta com Curitiba. Este é caracterizado por uma materialização do fenômeno da periferização, com rotinas diárias de moradores em deslocamento ao pólo regional para fins de desenvolvimento de muitas funções como profissional (trabalho e emprego) principalmente, mas também de consumo, educação, recreação, tratamento de saúde e outras.

Ao inverso, a área conhecida como Guarituba constitui-se em um tópico de especial atenção, não apenas por parte da administração municipal mas, principalmente pela coordenação do planejamento regional, que trabalha com a visão sistêmica da realidade metropolitana e as interações de cada caso com o conjunto.

\section{Guarituba}

Voltando um pouco no tempo para entender o processo em foco, verifica-se que há cerca de 50 anos atrás, provavelmente seria difícil imaginar a escala de crescimento que a região iria experimentar nas décadas seguintes. $\mathrm{Na}$ década de 50, Curitiba era uma pacata cidade com cerca de 180.000 habitantes, enquanto Piraquara não ia além de 6.900 moradores. No entanto, nessa década foram aprovado, 21.000 lotes no município, enquanto o quantitativo de habitantes era pequeno. Essa situação pouco modificou-se na década seguinte, a não ser pelo fato de serem aprovados inúmeros projetos de loteamentos nesta porção leste, da futura região metropolitana(e em outras porções também, como ao norte, nos anos 70), apesar das condições precárias desta região de mananciais, sujeita a inundações, distante dos centros urbanos e sem nenhuma infra-estrutura.

FONTE: COMEC, 1998.

21 Observa-se que mesmo medidas legais, aprovadas no período, não foram suficientes para estancar o processo de ocupação de áreas inadequadas para habitação, como do Guarituba. De âmbito estadual, foi aprovado o Decreto n. ${ }^{\circ} 2964 / 80$ que declara de interesse e proteção especial as áreas das bacias dos rios que compõe os mananciais e recursos hídricos de interesse da região metropolitana de Curitiba. Também, a lei estadual n. ${ }^{\circ}$ 8935/89, que dispõe sobre os requisitos mínimos para as águas de mananciais de abastecimento público (COMEC, op. cit., p. 35). 
LIMA, C. A. Considerações sobre ocupações irregulares e parcelamento urbano...

TABELA 4 - MUNICÍPIO DE PIRAQUARA - LOTEAMENTOS APROVADOS POR DÉCADA 50, 60, 70,80 e 90

\begin{tabular}{|c|c|c|c|c|c|c|c|c|c|}
\hline Década & N. ${ }^{\circ}$ LOTEAM & MENTC & & N. ${ }^{\circ}$ LOIES & & & ÁREALOTI & $\operatorname{EADA}\left(\mathrm{m}^{2}\right)$ & \\
\hline & GUARITUBA & SEDE & TOTAL & GUARITUBA & SEDE & TOTAL & GUARITUBA & SEDE & TOTAL \\
\hline 50 & 82 & 35 & 117 & 11.658 & 8.964 & 20.622 & $9.413 .190,62$ & $6.092 .399,45$ & $15.505 .590,07$ \\
\hline 60 & 11 & 21 & 32 & 1.134 & 3.932 & 5.066 & $1.185 .223,10$ & $4.978 .152,61$ & $6.163 .375,71$ \\
\hline 70 & 8 & 7 & 15 & 612 & 398 & 1.010 & $1.173 .379,15$ & $1.785 .071,80$ & $2.958 .450,95$ \\
\hline 80 & 6 & 7 & 13 & 957 & 2.121 & 3.078 & $1.530 .823,90$ & $7.032 .823,51$ & $8.563 .647,41$ \\
\hline 90 & - & 2 & 2 & - & 189 & 189 & - & 191.248,91 & \begin{tabular}{|l|}
$191.248,91$ \\
\end{tabular} \\
\hline TOTAL & 107 & 72 & 179 & 14.361 & 15.604 & 29.965 & $13.302 .616,77$ & $20.079 .696,28$ & $33.382 .313,05$ \\
\hline
\end{tabular}

FONTE: COMEC, 1998.

Os anos setenta vieram trazendo a época do "milagre brasileiro" e a repercussão regional foi, entre outros fatores, de acelerado crescimento de população formada por pessoas com perfil profissional e cultural vinculado às atividades de pequena agricultura e ao ambiente rural de forma geral. No município de Piraquara, a região "colada" à divisa com Curitiba, apresentou cerca de um terço da quantidade de área loteada comparativamente à década anterior. Esta área viria mais tarde a conformar o município de Pinhais.

Esse tipo de ocupação, alheia aos planos urbanos regionais adensa-se e consolida-se nas décadas de 70 e 80 , conformando conurbação com Curitiba. No entanto, enquanto na sede municipal - Piraquara - o crescimento equiparava-se a Guarituba em quantidade de novos loteamentos, a área loteada no perímetro da sede, na década, era de quase cinco vezes maior, ou seja, as áreas dos lotes eram maiores porque esses loteamentos na sede atendiam a uma clientela de maior poder aquisitivo do que aquela fixada na região de Guarituba. Tal fato fica mais claro ao observarse comparativamente as áreas loteadas na sede e no Guarituba, nas décadas de 50 até 90 , conforme o gráfico 4 .

Esse fato é característico de fenômeno de periferização das camadas mais carentes da população regional, e permite avaliar a capacidade de polarização exercida por Curitiba, que nos anos oitenta, se reforça, desalinhando possibilidades de um equilíbrio metropolitano centrado no fortalecimento das sedes municipais regio- nais, preconizado pelas diretrizes do Plano de Desenvolvimento Regional - PDI, aprovado ao final da década anterior.

A Comec - sustentava suporte técnico para implantação das bases legais e estrutura de planejamento urbano nos municípios da RMC, por escala de prioridades, definidas em função dos problemas e riscos existentes. Assim foi que Piraquara passou a contar com Plano Diretor em 1980. Essa legislação reforçava as macro-diretrizes regionais estipuladas para as áreas de mananciais pelo PDI : contenção da urbanização. Também a Lei Federal n. ${ }^{\circ}$ 6.766/ 79 que dispõe sobre o parcelamento urbano coibia o parcelamento inadequado e deficiente. $\mathrm{O}$ mercado imobiliário, agora subjugado pelas leis de uso e ocupação do solo em vigor, praticamente estagnou-se ao ver reduzidas suas possibilidades de lucro devido às exigências e restrições legais aplicadas aos loteamentos aprovados, porém não ocupados, ou novos loteamentos, conforme os dados da tabela 4 .

Com a Lei Federal n. ${ }^{\circ} 6799 / 79$, interrompeu-se a fase de grande quantidade de novos loteamentos. Segundo Comec, "a legislação restritiva à nível municipal e estadual, aliada à ausência de infra-estrutura, foram suficientes para impedir até meados de 80 que esses loteamentos fossem ocupados legalmente." 22

A quantidade de loteamentos aprovados legalmente foi substancialmente maior nas décadas anteriores, como anos sessenta e setenta. A partir de oitenta, passam a inten- 
sificar-se ocupações irregulares, como as que ocorreram na região do Guarituba, sobre parcelamentos antigos, aprovados legalmente. ${ }^{23}$ As ocupações ilegais e invasões sobre áreas públicas ou privadas são fatos na RMC na década de 90, quando a demanda habitacional da população de renda mínima aumentava rapidamente. O Guarituba passa a retratar esse crescimento dos assentamentos precários. Dados de 1997, levantados pela Comec, demonstravam a existência de 40 pontos de invasão no Guarituba, perfazendo um total de 3.411 unidades de moradia, "que correspondem a $81 \%$ das invasões existentes no município". Do total de invasões no município de Piraquara levantadas em 1997 (COMEC, 1999), a proporção de $85 \%$ localizou-se no Guarituba e também, do número de unidades habitacionais no município, $81,17 \%$ localizam-se no Guarituba. Das moradias em área de invasões no Guarituba, $84,17 \%$ estavam assentadas em áreas particulares, $13,37 \%$ estavam em área da prefeitura e 2,45\% localizavam-se sobre ruas.

Também é importante verificar a quantidade de área loteada do município, e o quanto representam do território regional. No total territorial do município, 14,83\% já estão loteados, sendo que menos de $6 \%$ situam-se no Guarituba; na sede e a área loteada da sede é de 8,92\%. Apesar de haver ainda bastante área livre, o município de Piraquara não é vocacionado para a uma urbanização mais intensa, principalmente devido a presença dos mananciais de abastecimento público e a Serra do Mar.

Atualmente, a ocupação do solo é predominantemente urbana. Observa-se uma conformação de adensamento progressivo em direção à sede urbana. Também nas bacias dos rios Itaqui e Iraí há concentração de habitações unifamiliares. O uso comercial encontra-se disseminado por entre as moradias, e também uma porcentagem incipiente de uso industrial. O trabalho desenvolvido na Comec que organiza os diversos tipos de uso do solo através de número de consumidores da Copel, permite a visualização da situação.

De maneira geral, há uma transformação em processo no município, destacando-se a pressão sobre usos de solo tradicionais para cederem espaço ao uso habitacional de alta densidade. Exemplos são as chácaras, tanto aquelas destinadas à recreação e lazer como as de produção primária. Neste sentido, a Comec posiciona-se em relação às condições ambientais, dizendo que
Há que se considerar, também, que essa substituição das atividades agrícolas por habitações de alta densidade, constitui-se numa ameaça à qualidade hídrica, tanto pela impermeabilização excessiva do solo, como pelo lançamento de efluentes domésticos. Existem no local, apenas alguns remanescentes florestais com interesse de preservação, situados em propriedades particulares. Nas terras marginais aos principais rios da região, verificase a manutenção da mata ciliar dos rios Piraquara e Itaqui, com a ocorrência de muitas ocupações nas margens do rio Iraí (COMEC, 1998, p. 42). ${ }^{24}$

Devido à própria conformação de relevo, tipo de solo, subsolo, e rede hidrográfica, a localização do município de Pinhais e seus vizinhos como Piraquara e São José dos Pinhais, têm áreas em seu território - como a de Guarituba que apresentam características como nível de lençol freático aflorante, suscetibilidade à inundações e assoreamento dos cursos d'água devido a ocupação ou movimentações de terra nas suas margens, várzeas inadequadas à ocupação para assentamentos humanos. O escoamento superficial natural das águas e mesmo os fluxos de redes de serviços públicos como de água e esgoto, é bastante dificultado devido às declividades locais serem baixas. $\mathrm{O}$ resultado das condições naturais é um quadro de pântano, terras baixas, alagadiças, também conhecidas pelo nome de atoleiro, lamaçal, charco, banhado ou brejo.

Segundo Comec (1999), as várzeas na região do Guarituba são alagadas principalmente em função

(da) elevação das águas do rio Iraí e de seu efeito de represamento sobre as águas dos rios Piraquara e Itaqui. Nesses locais, será necessária a execução de obras de drenabilidade para rebaixar o nível freático e assim aumentar o escoamento superficial e diminuir o encharcamento do solo. Em função desse problema, foi previsto, no âmbito do Prosam, a execução de obras de macro-drenagem para o rio Iguaçu. A obra, já parcialmente executada, consiste em um canal paralelo ao Iguaçu, em sua margem esquerda, para drenar os afluentes desta, ocorrendo significativa diminuição das áreas atingidas pelas cheias, e permitindo a ocupação de áreas hoje sujeitas a alagamento. ${ }^{25}$

23 COMEC, UTP..., op. cit., p. 19.

24 Grifo nosso.

25 Ibid., p. 25. 
LIMA, C. A. Considerações sobre ocupações irregulares e parcelamento urbano...

Em função de muitas dessas áreas alagadiças estarem ocupadas por assentamentos humanos, legalmente aprovados ou não, as obras de drenagem previstas configuram-se em duas linhas de ação: um conjunto de canais não revestidos para rebaixar o lençol freático sem aumentar a velocidade dos escoamentos e, por outra linha, reservatórios, nos lotes ocupados, visando compensar a impermeabilização causada pelas construções. Futuramente, segundo Comec, a proposta se completará com o sistema de esgotamento sanitário da área completamente separado do sistema de drenagem.

Como ponto de destaque da temática, no município de Piraquara, cabe salientar que as vias existentes na área do Guarituba são originárias de antigas estradas, como as da Fazenda Guarituba que existiu no local, e outros caminhos que levavam à sede municipal de Piraquara, como a atual Rodovia PR-415. Essa rodovia e o acesso principal à sede do município são as vias principais da localidade. Os desmembramentos implantados nas décadas de 40 e 50 basearam-se nas duas vias, para justificar a comercialização dos lotes na qualidade de terrenos urbanos. As ruas existentes são aquelas traçadas na implantação dos loteamentos. Esse conjunto não apresenta pavimentação de qualquer tipo, a continuidade das ruas é parcial, com interrupções no traçado e ocupações sobre o leito das ruas, sem qualquer hierarquia viária.

A Comec vêm trabalhando na implantação de várias unidades territoriais de planejamento, sendo a do Guarituba subordinada ao plano de uso do solo que foi submetido à aprovação do conselho gestor dos mananciais da região metropolitana de Curitiba em sua 2. ${ }^{a}$ reunião ordinária. A Comec considera que, devido ao caráter social do projeto, o sucesso da implementação do mesmo está vinculado à participação comunitária, sendo a base da proposta o

Marco inicial da operação de urbanização e recuperação das áreas degradadas do Guarituba, à partir do qual será estabelecido um protocolo de intenções entre os diversos agentes e um cronograma das ações a serem desenvolvidas na área. ${ }^{26}$

Partindo da avaliação do incremento populacional efetivado nos últimos vinte anos, ou seja, um incremento de 1.225.598 habitantes, a proposta chama a atenção para o que representa este número em termos de necessidade de equipamentos sociais e unidades de habitação. Considera também "o incremento populacional localizado em áreas de mananciais em áreas limítrofes ao polo metropolitano, cujo montante decuplicou em 26 anos" e também expressa aquiescência a respeito da impotência das restrições normativas em face às ocupações que ocorreram na região: "o crescimento populacional nas áreas de mananciais ocorreu apesar das restrições quanto ao parcelamento do solo previstas nas legislações estadual e municipal." ${ }^{27}$

A ocupação do Guarituba reveste-se de especial importância no quadro de ocupação urbana não apenas municipal, onde concentra $43,63 \%$ do total de habitantes do município (IBGE - contagem populacional 1996), mas inclusive a nível regional especialmente pelas implicações relativas à contaminação de mananciais e desagregação social. Já na década de 50, na qual Piraquara atingiu limites únicos em quantidade de lotes aprovados na região metropolitana, a localidade de Guarituba teve maior número de loteamentos aprovados que a própria sede. Dados da Fundepar demonstram que as matrículas nas escolas de ensino fundamental estabelecidas no Guarituba, no ano 1997 (3.402), representaram 36\% do total de matrículas do município de Piraquara.

No entanto, apesar da normatização referente à ocupação da área existir, assim como legislação específica para a proteção dos mananciais (Lei Estadual n. ${ }^{\circ}$ 8935/89 e a recente 12.248 de 31/07/98) prossegue a ocupação irregular da área. O órgão de planejamento regional no desenvolvimento de estudos sobre as situações tais quais à do Guarituba na RMC, entende que especialmente a porção leste regional deve ser alvo de atenção constante, devido às suas características fundamentais no equilíbrio ecológico da região metropolitana. Sugere duas linhas mestras para a abordagem da situação: uma relativa aos aspectos da drenagem natural (saneamento, qualidade dos mananciais de abastecimento público de água e controle de inundações) e a outra sobre a cobertura vegetal existente.

\section{Conclusão}

A forma como acontece a ocupação do solo mantém estreita conexão com os problemas ambientais. A eloqüên- 
cia de dados como os referentes ao crescimento das ocupações irregulares, que aliam quadros de degradação humana com degradação de recursos naturais, reforça a necessidade de estudar a trajetória que gerou a crise ambiental na RMC, nas feições socioeconômica e dos recursos hídricos. A ocupação inadequada do solo regional foi em grande parte originada na primeira metade do século XX, notavelmente pelos loteamentos dispersos e sem infra-estrutura da periferia das sedes municipais nas bordas de Curitiba, e que deveriam ficar congelados, sem utilização segundo práticas conservacionistas, como estipulado no PDI, em 1978. No caso da ocupação dos mananciais do leste metropolitano, como na localidade do Guarituba, tem-se um perfil do quadro regional a ser abordado nesse aspecto.

As políticas públicas de ordenamento territorial têm sido pouco apoiadas pelas ações de governo, pois não há como serem implementadas ou obedecidas quando inexistem ações que prestem atendimento as demandas básicas como habitação, emprego, formação profissional e apoio sociocultural. Uma sinalização da degradação ambiental na RMC consiste na esterilidade dos poucos itens do Plano de Desenvolvimento Integrado - PDI, aprovado em 1978, que mereceram a devida implementação. Nesse sentido, cabem preocupações quanto ao prosseguimento do processo de ocupação metropolitana, que a partir de 1996, encontra-se mais acelerado na periferia do município de Curitiba, agravando ainda mais deficiências registradas anteriormente, especialmente infra-estrutura básica e serviços urbanos. Cerca de $88 \%$ do crescimento metropolitano refere-se a população que habita o pólo e seus vizinhos imediatos. Ao mesmo tempo, esse crescimento leva ao esgotamento de mananciais de abastecimento público de água que supre $69 \%$ do sistema Curitiba, responsável pelo abastecimento da capital Curitiba, São José dos Pinhais, o município mais populoso da RMC, depois do pólo, parte de Colombo, Pinhais e Araucária. Estes são alguns dos municípios mais populosos da região metropolitana.

A existência de um plano de desenvolvimento regional não impediu a degradação do meio ambiente, sobretudo de recursos naturais fundamentais a vida, como no caso da água. Com certeza, este caso não é o único no mundo em que os planos ficaram engavetados enquanto a dinâmica da realidade tornava-os obsoletos. A decisão pela implentação dos planos cabe aos representantes da população, que são eleitos para resguardar o bem comum No caso do PDI/78 e a RMC em relação aos mananciais de abastecimento público de água, considera-se importante refletir tendo em vista o futuro do espaço metropolitano.

Um aspecto que está implícito na questão é o político, pois tendo sido a população lesada pela degradação dos mananciais de abastecimento público de água, tendo pago por um Plano de Desenvolvimento Integrado - PDI/1978, que iria, estabelecer diretrizes para a ocupação equilibrada da região e evitar perdas ambientais importantes, como dos mananciais, remete-se às responsabilidades dos ocupantes dos cargos públicos e ao processo de tomada de decisão que vai além dos aspectos técnicos de planejamento. $\mathrm{O}$ esgotamento dos mananciais do leste metropolitano em 35 anos configura uma situação ambiental muito grave na RMC. A análise dos fatos levantados nesse artigo vem demonstrar que um dos pontos fundamentais a que essa crise aponta é a participação do cidadão na supervisão das tomadas de decisão sobre os bens comuns. Em tempos de liberalismo, cabe ao citadino assumir o papel do cliente, proprietário dos bens e recursos coletivos e aquele que paga pelo serviço, enquanto o político ou o servidor público, são seus empregados, que recebem para trabalhar a favor do cliente.

A gestão ambiental-metropolitana pode ser trabalhada a partir do recortes definidos pelas dinâmicas do meio ambiente como as bacias hidrográficas. No entanto, considera-se que talvez o item mais importante para a gestão ambiental não tornar estéril, como as experiências passadas do planejamento urbano e regional, está em dotar os organismos de gestão ambiental - que inclui a participação cidadã - de poder de implementação das políticas, em articulação com as demais que são interligadas a ela. Como se verifica na trajetória de planejamento urbano da RMC, os estudos e propostas foram feitos, sendo exemplo o PDI/ 1978 e suas reavaliações e outros tantos trabalhos, que foram efetivados na realidade conforme a disponibilidade de recursos humanos, financeiros ou de decisão política. Desde sua criação 1973, as regiões metropolitanas do país foram tolhidas do poder de implementação, mantendo o clientelismo municipal individualista. Parece conveniente pensar-se sobre alguma forma de poder para as metrópoles que daria o suporte necessário para a implementação das ações conjuntas entre os municípios visando conservação integrada de usos e recursos.

A gestão do espaço metropolitano, mesmo por força do esgotamento dos recursos naturais, começa a articularse na dimensão ambiental, como determinante para as ações de governo, e nesta escala de ações estruturais e não estru- 
LIMA, C. A. Considerações sobre ocupações irregulares e parcelamento urbano...

turais, as políticas públicas estarão concluídas com a sua implementação e rearticulação constantes, o que apenas será viabilizado quando os citadinos se tornarem cidadãos, es- tando convictos dos valores comuns, tanto da ética entre humanos como da responsabilidade de cada um para com a biosfera.

\section{REFEREANCIAS}

ANDREOLI, A. et al. Limites ao desenvolvimento da região metropolitana de Curitiba impostos pela escassez da água. Sanare, Curitiba, n. 12 , p. 31-42, jul./dez. 1999.

BONDUKI, N. Crise na habitação e luta pela moradia no pós-guerra. In: KOWARICK, L. (Org.). As lutas sociais e a cidade. São Paulo: Paz e Terra, 1988.

COMEC. Cadastro Metropolitano de loteamentos. UTP Guarituba. Curitiba, 1998.

Metrópolis em revista. Curitiba, 1999.

Plano de desenvolvimento integrado da região metropolitana de Curitiba. Curitiba, [1987?].

Proposta para área de interesse social AISO do Guarituba/Piraquara. Curitiba, 1999.
Unidade Territorial do Guarituba. Curitiba, 1998.

DALARMI, O. Utilização futura dos recursos hídricos da região metropolitana de Curitiba. Sanare, Curitiba, v. 4, n. 4, p. 31-43, abr./maio/jul. 1995.

IBGE. Censo populacional 1991. Rio de Janeiro, [1992?]. . Contagem populacional 1996. Paraná, 1999. [1997?].

Contagem populacional 1996. Rio de Janeiro,

LIMA, C. de A. A ocupação de áreas de mananciais na região metropolitana de Curitiba: do planejamento à gestão ambiental urbano-metropolitana. Curitiba, 2000. Tese (Doutorado em Meio Ambiente e Desenvolvimento), Universidade Federal do Paraná. 